\title{
A IMPORTÂNCIA DA AVALIAÇÃO DE MATERIAIS DIDÁTICOS PARA A EAD: UM ESTUDO DE CASO
}

\author{
THE IMPORTANCE OF TEACHING MATERIAL EVALUATION: A CASE STUDY
}

Márcio Mota Pereira ${ }^{1}$

Escola de Ciência da Informação, Universidade Federal de Minas Gerais

\begin{abstract}
Resumo
Este artigo analisa um material didático impresso utilizado no âmbito da $\mathrm{EaD}$, no curso de aperfeiçoamento "Educação de Jovens e Adultos na Diversidade", oferecido pela Universidade Federal de Minas Gerais, e é resultado de uma pesquisa maior, que abordou um mote ainda pouco presente no universo dessa metodologia de ensino; a avaliação de materiais didáticos para a Educação à Distância. Neste artigo, enquanto estudo de caso, observou-se que o material didático em questão foi confeccionado em consonância com a concepção pedagógica "contra-hegemônica", e que sua diagramação viabilizou a legibilidade textual; que o conteúdo principal foi redigido com a devida formalidade acadêmica, e que apresenta coesão e coerência na sequenciação de ideias e dos conteúdos. Por outro lado, verificou-se também a necessidade da realização de revisões que contemplem aspectos considerados essenciais para a consolidação de conhecimentos no âmbito da metodologia de Ensino EaD, como uma maior presença de fotografias e ilustrações, responsáveis por tornar o material didático mais atrativo, assim como resumos pós conteúdos, essenciais para a consolidação de conhecimentos adquiridos.
\end{abstract}

Palavras-chave: Educação a Distância, Educação de Jovens e adultos, Avaliação de material didático impresso.

\begin{abstract}
This article analyzes a printed teaching material used on E-learning course, named "Youth and Adult Education in Diversity", offered by the Federal University of Minas Gerais, and is the result of a larger research about the evaluation of didactic materials for Distance Education. In this article, a case study, we looking to identify if the didactic material in question was made in line with the "counter-hegemonic" pedagogical techniques, and its layout enabled the textual readability; which main content was written with due academic formality and which presents cohesion and coherence in the sequence of ideas and contents. On the other hand, there was also the need to perform analyzes that consider aspects considered critical for the application of knowledge in the teaching method, such as a greater presence of photographs and illustrations, helping to make the most used teaching material, as well as abstracts, essential for the development of acquired knowledge.
\end{abstract}

Keywords: Distance Education; Youth and Adult Education; Evaluation of printed learning materials.

\section{INTRODUÇÃO}

As tecnologias virtuais ampliaram as possibilidades de indexação (classificação/sistematização) da informação/conhecimento de tal forma que podem ser acessadas desconsiderando o fenômeno espaço/tempo. O ensino presencial e a distância vem se apropriando

\footnotetext{
${ }^{1}$ Doutor em História, Universidade Federal de Minas Gerais. Mestre em Bens Culturais, Fundação Getúlio Vargas. Especialista em Planejamento, Implementação e Gestão da EaD, Universidade Federal Fluminense. Graduado em História, Universidade Federal de São João del-Rei. Professor Substituto da Escola da Ciência da Informação, da Universidade Federal de Minas Gerais. E-mail: drmmota@yahoo.com.br
} 
das ferramentas virtuais de desenvolvimento científico/tecnológico e revolucionando a relação dos estudantes com o conhecimento. Tal cenário pode ser interpretado como uma solução viável para o déficit educacional vivenciado em nosso país (CARVALHO et al, 2013).

Nesse contexto, é imprescindível o desenvolvimento de situações favorecedoras à rápida adequação do discente ao processo de ensino virtual. Os materiais didáticos são, portanto, os meios didáticos/pedagógicos imprescindíveis aos processos de ensino e de aprendizagem. Entende-se material didático como uma expressão abrangente na qual estão inseridos todos os recursos, modalidades e procedimentos com finalidade intencional de ensino. É o processo pelo qual se estabelece a comunicação entre professor/estudantes e estudantes/estudantes. No entanto, autores como Ota et al (2013) assinalam a importância de estudos analíticos relacionados a qualidade dos cursos de $\mathrm{EaD}$, bem como, dos materiais didáticos utilizados nessa modalidade de ensino.

Entre os recursos didáticos utilizados em $\mathrm{EaD}$ o material didático impresso é o que predomina por ser de fácil acesso e de baixo custo. Segundo Silva (2010, p.15) "a qualidade do ensino em EAD passa, principalmente, por um bom material didático impresso, pois este se constitui na fonte principal de consulta de alunos para aprendizagem". Nessa perspectiva, esse trabalho desenvolve uma reflexão, na abordagem qualitativa, sobre material didático impresso utilizado em um curso de EaD. Esse estudo apresenta parte dos resultados de uma pesquisa (monografia) do curso de pós-graduação Lato Sensu Planejamento, Implementação e Gestão da EaD oferecido pela Universidade Federal Fluminense (Pereira, 2018).

\section{EMBASAMENTO TEÓRICO E METODOLOGIA}

Neste trabalho foi analisado, na abordagem qualitativa, o material didático impresso intitulado "Educação de Jovens e Adultos na Diversidade" elaborado como suporte didático para o curso de Aperfeiçoamento Educação de Jovens e Adultos na Diversidade oferecido pela UFMG, na modalidade $\mathrm{EaD}$, para professores que atuam na educação de jovens e adultos. O livro didático foi confeccionado em volume único e disponibilizado nos formatos virtual (PDF) e impresso.

Os critérios de análise estão relacionados as características da diagramação/design gráfico. No contexto da produção de materiais didáticos para a EaD, a de se destacar dois conceitos: arquitetura da informação e design instrucional. Na concepção de Reis $(2007$, p. 63) “a arquitetura da informação é responsável por definir o esqueleto que organiza as informações sobre a qual as demais partes irão se apoiar." Em material didático impresso pode-se situar arquitetura da informação como a organização estrutural da informação (planejamento visual e gráfico, legibilidade, uso de cores, ícones, informações periféricas, entre outros (PRETI, 2010). 
Filatro (2004, p. 5) define design instrucional como uma...

[...] ação institucional e sistemática de ensino, que envolve o planejamento, o desenvolvimento e a utilização de métodos, técnicas, atividades, materiais, eventos e produtos educacionais em situações didáticas específicas, a fim de facilitar a aprendizagem humana a partir dos princípios de aprendizagem e instrução conhecidos.

Em material didático impresso pode-se situar design instrucional como desenho didático/pedagógico: planejamento pedagógico (orientação teórica e metodológica), sequenciamento didático, analogias, linguagem (clara, precisa, conectiva, coesão, coerência, dialógico, hipertextual), atividades (interativas, autoavaliativas, avaliativas), entre outros (Barreto, 2007).

A análise qualitativa empreendida fundamenta-se em estudos de autores que investigam esse tema. Estas pesquisas ressaltam que o material didático impresso planejado e elaborado para a $\mathrm{EaD}$ devem apresentar características como: interatividade, conectividade, legibilidade, diagramação que busque dar forma adequada à apresentação do texto/hipertexto, embasamento teórico/metodológico, relação teoria/prática, autoavaliação e avaliação, linguagem/vocabulário clara e concisa, exemplificações cotidianas e científicas, resumos e sugestões de informações complementares. Tais características devem adequar-se, obviamente, as mídias veiculadoras.

\section{RESULTADOS E DISCUSSÃO}

\subsection{Marco teórico/metodológico}

No sentido de construir um marco teórico e metodológico do material impresso para o curso de "Aperfeiçoamento Educação de Jovens e Adultos na Diversidade", os organizadores estabelecem, em princípio, a superação de três desafios: O primeiro desafio é o reconhecimento de que existe uma dívida social do Estado Brasileiro que negligenciou a educação das camadas populares relegando-as a condição de párias da sociedade. Os autores reconhecem que a educação escolar é um dos principais direitos sociais do indivíduo na construção de sua cidadania. Nesse sentido a educação de jovens e adultos estabelece um marco de superação dessa dívida social, político e histórica. O segundo desafio é a valorização da cultura e da educação popular na qual o indivíduo se vê como ser social inserido num contexto social, político e histórico mais amplo. Nessa perspectiva o ensino de jovens e adultos deve ser planejado no sentido de promover o processo de culturação. O terceiro desafio é realçar a especificidade da educação de jovens e adultos como sendo uma modalidade educacional destinada a adultos (jovens, adultos e idosos). Isso exige um olhar para o planejamento dessa prática educativa que deve levar em consideração as visões de 
mundo dos jovens e adultos, bem como suas expectativas de vida e, principalmente, suas diferenças cognitivas (SOUZA, 2013).

O ensino de jovens e adultos tem o papel fundamental de inclusão social das camadas populares. No entanto, os autores colocam que a superação desses três desafios está condicionado a mudança da visão mercadológica de que a educação das camadas populares deve estar associada a formação para o trabalho. A educação tem que ser entendida como um direito universal do ser humano não importando sua idade ou sua condição socioeconômica; e, também, como um dever do Estado para com seus cidadãos (SOUZA, 2013).

Conforme a reflexão delineada, o planejamento pensa o plano de ensino sob a ótica de uma concepção pedagógica. Segundo Saviani (2008, p. 167), “[...] em termos concisos, podemos entender a expressão 'concepções pedagógicas' como as diferentes maneiras pelas quais a educação é compreendida, teorizada e praticada." Nessa linha de pensamento, o plano didático é pensado e elaborado buscando-se a materialização do discurso pedagógico. O discurso delineado pelos autores situa a orientação teórica e metodológica do material impresso dentro de um conjunto de concepções pedagógicas que Saviani denomina de "contra-hegemônicas" (libertadora, libertária, histórico-crítica, educação popular, etc.). Essas concepções atuam no processo de ensino/aprendizagem de forma intencional e sistemática buscando a transformação do modelo socioeconômico vigente.

$\mathrm{Na}$ sequência desse pensamento Sales $(2005$, p. 3) evidencia a seguinte ideia:

$$
\begin{aligned}
& \text { O material didático para } \mathrm{EaD} \text { é um elemento mediador que traz em seu bojo a concepção } \\
& \text { pedagógica que norteia o ensino/aprendizagem. Consciente ou inconscientemente, o } \\
& \text { planejamento e a constituição do material didático que mediara situações de ensino } \\
& \text { aprendizagem, está intimamente relacionado a concepção pedagógica do produtor deste } \\
& \text { material. }
\end{aligned}
$$

Buscando a materialização de seu discurso teórico/metodológico, os autores estruturaram o material didático em seis módulos, que se subdividem em várias unidades tratando de diversos aspectos teóricos e práticos acerca da Educação de Jovens e Adultos: a) 'Introdução à EaD' discorre sobre a temática da Educação de Jovens e Adultos, apresentando concepções e funções da EJA; b) 'Educação de Jovens e Adultos na Diversidade' aborda temas distintivos dessa modalidade: a linguagem, a condição de não criança, o espaço de sala de aula, as mudanças na vida do discente em função da alfabetização, a inserção subordinada dos sujeitos de EJA no mundo do trabalho, a identidade do educador de EJA; c) 'Políticas Públicas da EJA' contextualiza historicamente essa modalidade de ensino, sublinhando sua legislação e suas políticas educacionais; d) 'Aspectos Pedagógicos da EJA' discute sobre concepções de ensino e aprendizagem e suas implicações para essa modalidade; e) 'EJA e o Mundo do Trabalho' abre debate sobre o peso do mundo do trabalho no processo de escolarização da Educação de Jovens e Adultos; f) 'Projeto Integrado e Participativo 
em Educação na Diversidade' discute as tecnologias sociais participativas e a importância do protagonismo dos sujeitos, dessa modalidade, no processo educativo (SOUZA, 2013).

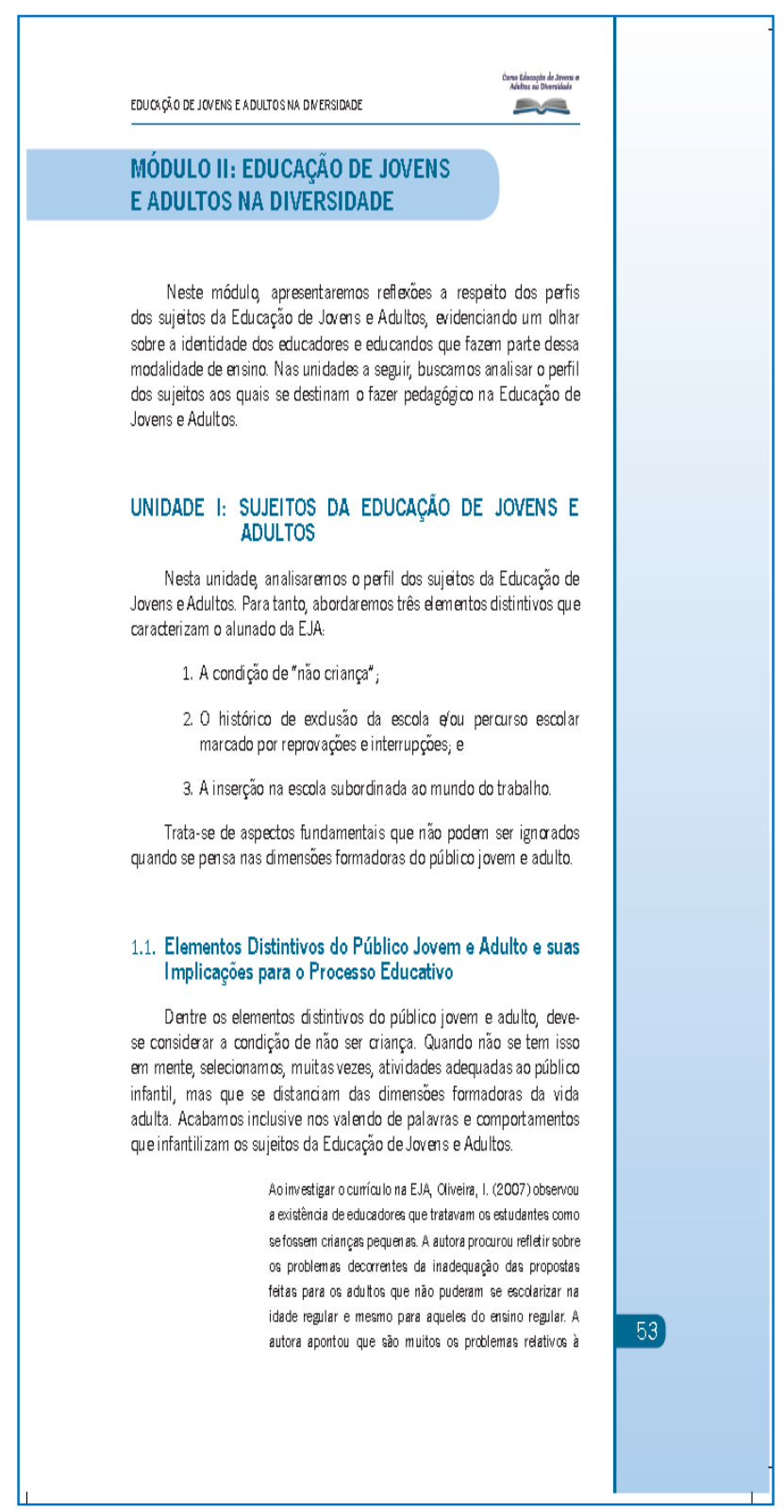

Figura 1: Exemplo da diagramação da obra analisada. In: SOUZA, Antônio Artur de (Org.). Educação de Jovens e Adultos na Diversidade. Belo Horizonte: CAED-UFMG, 2013, p. 53.

\subsection{Diagramação/Legibilidade}

Diagramação/design gráfico é a organização dos elementos gráficos da página impressa e/ou virtual. A estruturação tipográfica e a legibilidade são aspectos essenciais da diagramação. A legibilidade é um dos itens importantes na confecção de material didático para a EaD. A escolha 
da fonte, seu corpo e contraste com o fundo, as entrelinhas entre as frases, o espaçamento entre os parágrafos e as palavras, a visibilidade textual e gráfica devem facilitar e estimular a leitura, compreensão e percepção da informação a ser apreendida por pessoas de diversas faixas etárias. Nesse sentido a legibilidade viabiliza a compreensibilidade (leiturabilidade) do texto (conteúdo) a ser apreendido intelectualmente pelo estudante (LIMA, 2007; SAMPAIO, 2002).

$\mathrm{Na}$ redação do material impresso analisado foi utilizada a fonte Arial. Os textos-base foram redigidos em corpo doze, de cor preta contrastando com fundo branco. Os títulos dos módulos estão redigidos em caixa alta de corpo catorze na cor azul de tonalidade escura dentro de um molde azul-claro o que deixa explícito o início de um novo assunto. Os títulos das unidades estão redigidos em caixa alta de corpo catorze na cor azul de tonalidade mais clara e sequenciados numericamente. Os subtítulos das unidades estão redigidos em caixa baixa de corpo catorze na cor azul de tonalidade mais clara e numerados seguindo o sequenciamento das unidades e dos subtópicos apresentados evidenciando, assim, o início e o término de algum tópico. As citações estão redigidas em corpo dez seguindo as normas da ABNT. [Figura 1]

Observa-se, portanto, que a redação do texto principal apresenta sequenciamento e articulação entre os temas possibilitando a estruturação dos conteúdos. Os parágrafos dos textosbase foram construídos com frases curtas. O espaçamento entre os parágrafos, as frases e as palavras os delimita visivelmente. Essas variações tipográficas mantêm a unidade gráfica e didática do material impresso; proporcionando, assim, uma leitura legível e compreensível. Nesse sentido, Sampaio (2002, p. 34) afirma que "[...] a clareza no design gráfico e a consistência nas informações promovem a facilidade na aquisição do conhecimento".

Os textos-base são complementados por caixas de informações periféricas que estão bem destacadas do corpo gráfico do texto. Os textos redigidos nas caixas periféricas seguem os mesmos padrões tipográficos delineados para o texto principal. Os boxes apresentam formato retangular e estão preenchidos por um tipo de cor (cinza ou azul-claro ou azul-escuro). [Figura 3] Apenas as caixas periféricas de dicionário (em formato de caixa de diálogo) estão localizados nas colunas laterais de cor azul-claro. Os textos estão redigidos em tamanho nove, o termo a ser explicado está destacado em cor de tonalidade azul e o restante em cor preta; ambos contrastando com o fundo branco da caixa periférica. [Figura 2] 


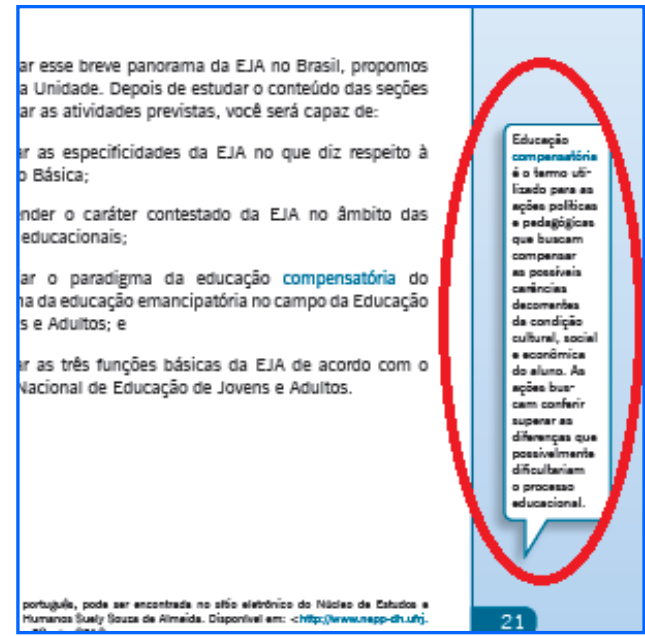

Diversidade. Belo Horizonte: CAED-UFMG, 2013, p. 21
Figura 2: Exemplo da diagramação da obra analisada. In: SOUZA, Antônio Artur de (Org.). Educacão de Jovens e Adultos na

Os recursos iconográficos presentes no texto restringem-se a chamar a atenção dos cursistas para as caixas de informações periféricas que estão sempre nomeadas por um termo como, por exemplo, através da palavra "importante" grafada em letras maiúsculas de tamanho catorze na cor vermelha à esquerda da caixa e, à direita, apresenta um ícone, que neste caso, é um ponto de exclamação na cor branca dentro de um círculo vermelho. Estes sinais gráficos e o realce cromático buscam evidenciar o tipo de caixa periférica apresentada após algum parágrafo do texto-base. [Figura 3]

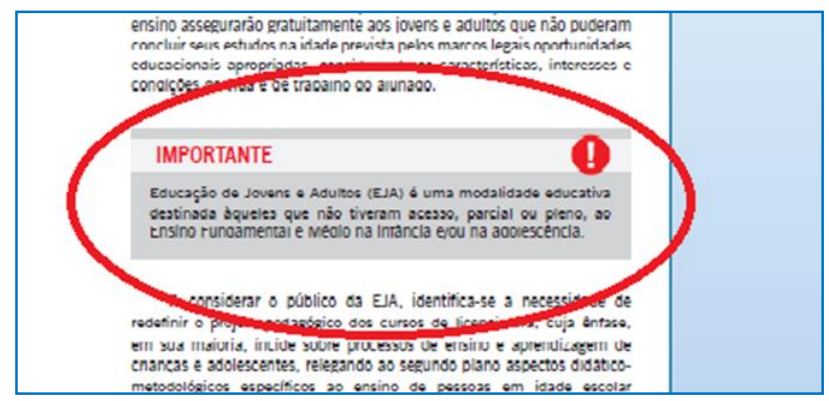

Figura 3: Exemplo da diagramação da obra analisada. In: SOUZA, Antônio Artur de (Org.). Educação de Jovens e Adultos na Diversidade. Belo Horizonte: CAED-UFMG, 2013, p. 35.

Kulpa et al (2011) assinalam que o uso de cores na construção gráfica é importante, pois realçam o visual, isto é, estimulam a sensibilidade humana, bem como o uso de ilustrações e ícones. Quanto a utilização de ilustrações o material didático impresso apresenta somente nove fotografias e duas tabelas (quadros). Ao longo dos textos-base não apresenta nenhum outro tipo de linguagem imagética.

Segundo Souza (2009), citando a Universidade Católica de Brasília, as imagens facilitam a compreensão do discurso textual. Uma ilustração pode substituir descrições ou sintetizar dissertações. Nesse sentido a qualidade (coloração, estética, forma, etc.) e o tipo (esquemático, 
documental, gráfico, tabelas, etc.) da ilustração esta impregnada de informações, viabilizando ao estudante pensar sobre os significados e significantes intertextualizados no texto:

\begin{abstract}
A imagem fomenta a motivação, facilita o conhecimento intuitivo, provoca a reflexão e impulsiona as relações interconceituais. Por outro lado, possibilita a compreensão de certas noções e conceitos que pela via textual seriam mais difíceis de adquirir. (UNIVERSIDADE CATÓLICA DE BRASÍLIA, p. 40).
\end{abstract}

Observa-se, portanto, que os diversos tipos de ilustrações favorecem a interatividade do estudante com o texto tornando-o mais agradável a leitura e realçando elementos como consultas, pesquisa, curiosidades, informações adicionais, conceitos, etc..

\title{
3.3 Informações Periféricas
}

Comumente os materiais didáticos impressos apresentam os textos-base de forma linear/contínua. As caixas de informações periféricas viabilizam o desdobramento do conteúdo por meio de recursos informativos complementares periféricos. Essa arquitetura instrucional rompe com a linearidade estática do texto principal conferindo-lhe aspecto de hipertexto. Essa característica hipertextual se configura na dinâmica informativa em movimento.

Essa dinâmica pode direcionar o estudante para dentro ou para fora do texto-base. Segundo Ramos et al (2007) o movimento para dentro da aula pode ocorrer por meio da 'caixa de ênfase' que destaca a importância de um determinado conteúdo, por meio da 'caixa de explicação expandida' que destaca a explicação complementar a algum item do texto base, e por meio da 'caixa de dicionário’ que apresenta verbetes e acepções de vocábulos. E o movimento para fora da aula pode ocorrer por meio da 'caixa de informação avulsa/curiosidade' que apresenta exposição nãoformal/informal de informações sobre algum item do conteúdo [Figura 4] e por meio da 'caixa de associação com outras mídias' [Figuras 4 e 5] que viabiliza a extrapolação dos limites do texto sugerindo a interação com outras mídias (livros, filmes, animações, seriados, documentários, sites, etc.).

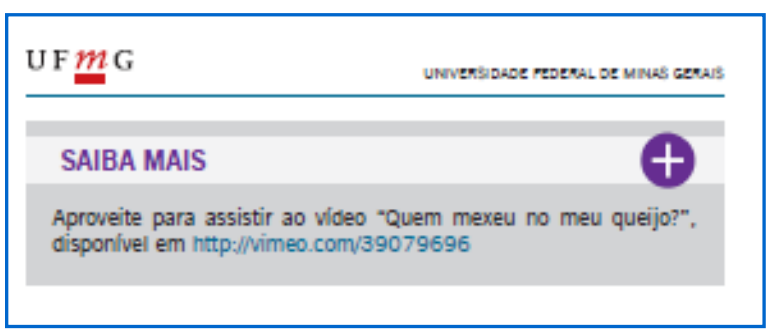

Figura 4: Exemplo de caixa de associação com outras mídias. In: SOUZA, Antônio Artur de (Org.). Educação de Jovens e Adultos na Diversidade. Belo Horizonte: CAED-UFMG, 2013, p. 78. 
A elaboração de material didático impresso para EaD deve promover o engajamento dos estudantes no seu processo de aprendizagem por meio de uma dinâmica de estudo não-linear. A utilização da arquitetura da informação no desdobramento do conteúdo central em conteúdos periféricos, viabiliza a construção de um design instrucional flexível, pois, possibilita aos estudantes vários caminhos de estudo. Nessa perspectiva o Designer Instrucional ao elaborar o texto principal deve destacar vocábulos, expressões, fatos, conceitos, e o que julgar relevante, e colocá-los em evidência por meio de boxes periféricos (expandindo a informação) para que o estudante possa ter opções de (re)construir seu conhecimento por meio de pesquisas, leituras complementares, análise de vídeos, etc.

Braglia e Gonçalves (2009) afirmam que é fundamental que o projeto de interface gráfica do material didático se mostre facilitador do acesso e da aprendizagem de modo a sensibilizar/motivar o estudante para seu conteúdo. É necessário que os dados textuais transmitam conteúdos fundamentados na pesquisa e que a escritura hipertextual proporcione múltiplas linguagens de interpretação e compreensão do tema em questão.

O material impresso em análise apresenta uma riqueza de caixas de informações periféricas com as seguintes nominações: 'importante', 'saiba mais', 'sugestão de leitura', 'atividade', 'dicionário/verbete', 'pesquise', 'para pensar', 'wiki', 'exemplo'. Observa-se que as caixas de informações periféricas apresentam uma característica interessante, elas podem apresentar mais de uma função. A função 'atividade' está implícita no desenvolvimento de praticamente todas as caixas de informações periféricas.

As atividades empreendidas, praticamente em todas as caixas de informações periféricas, possibilitam a aplicação do conhecimento teórico a realidade vivenciada pelo cursista, bem como, a análise dessa realidade a luz do referencial teórico em estudo. Esse aspecto é importante, pois promove aplicabilidade do conhecimento adquirido. Dessa forma promovem e incentivam as trocas de experiências criando subsídios (temas) para discussão nos fóruns temáticos. Estimulando a reflexão auxiliam o processo de autoavaliação. As caixas de atividades promovem várias formas de autoavaliação e de avaliação. Buscando coadunar pesquisa, reflexão e realidade, isto é, procuram subsidiar a prática cotidiana do professor da EJA com conhecimento teórico, mas, ao mesmo tempo, reconhecendo a singularidade de cada realidade e, que esta realidade, pode promover a ressignificação do conhecimento teórico.

Nesse sentido Averburg (2003, p.11) acentua que “Os problemas autênticos não costumam ter respostas unívocas ou facilmente previsíveis, envolvendo, na maioria dos casos verdadeiros, desafios cognitivos". [Figura 5] 


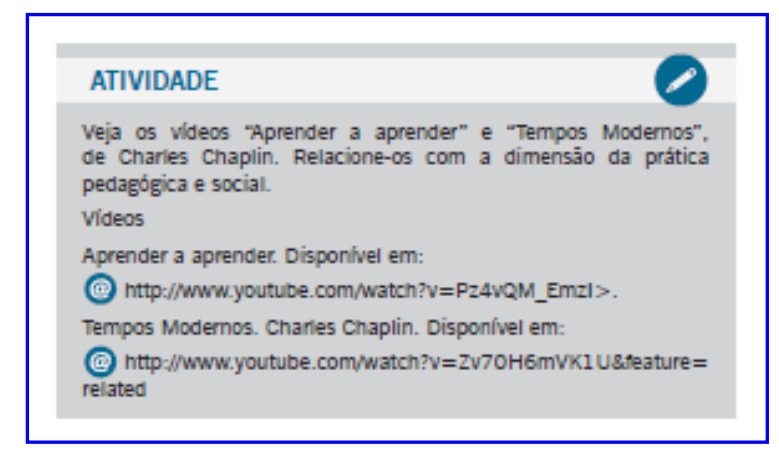

Figura 5: Indicação de atividades e exercícios para fixação do conhecimento. In: In: SOUZA, Antônio Artur de (Org.). Educação de Jovens e Adultos na Diversidade. Belo Horizonte: CAED-UFMG, 2013, p. 78.

Leitão et al (2005) ressaltam que os instrumentos aferidores devem ser complementares a aprendizagem para que o estudante avance no processo de (re)construção do conhecimento. Assinalam também a importância da abordagem baseada em problemas/desafios ressaltando o conhecimento da pedagogia da problematização como suporte teórico para se trabalhar as relações "teoria/prática" e "prática/teoria" no (re)conhecimento de que a prática educativa tem de ser epistemologicamente subsidiada para promover a (re)construção da práxis educativa.

\subsection{Texto/Hipertexto}

O material didático impresso foi disponibilizado também em formato digital PDF. O arquivo PDF preserva todas as configurações originais do documento (tipos de letra, gráficos, cores, formatações, paginações, etc.) e pode ser aberto em qualquer tipo de computador/plataforma. Por essas características configura-se como padrão de "virtualização impressa" de documentos e como um meio didático importantíssimo para o bom desempenho de cursos ministrados na modalidade EaD. A "virtualização impressa” disponibilizou aos estudantes acessar outros recursos midiáticos como vídeos (animações, entrevistas, relatos, etc), sítios (universidades, órgãos oficiais, jornais eletrônicos, revistas acadêmicas, etc), textos complementares, etc. A tecnologia da "virtualização impressa" viabilizou a "hipertextualidade" do material impresso.

Em uma análise inicial os textos-base são lineares e não apresentam características de hipertexto. Koch (2007, p. 24) apresenta a seguinte definição de hipertexto citando o glossário do Hypertext/Hypermedia Handbook, de Berk e Devlin (1991):

Hipertexto: a tecnologia de leitura e escrita não-sequenciais. $\mathrm{O}$ termo hipertexto refere-se a uma técnica, uma estrutura de dados e uma interface de usuário. [...] Um hipertexto (ou hiperdocumento) é uma coleção de textos, imagens e sons nós - ligados por atalhos eletrônicos para formar um sistema cuja existência depende do computador. O usuário/leitor caminha de um nó para outro, 
seguindo atalhos estabelecidos ou criando outros novos. (BERK; DEVLIN, 1991, p. 543).

No entanto, se levarmos em consideração que as caixas de informações periféricas viabilizam a conexão do texto principal com outras mídias e se visualizarmos o texto-base como uma construção intertextual e plurilinear podemos considerá-lo como um hipertexto. Como exposto no pensamento de Koch (2007, p. 28):

Penso, contudo, que a maior diferença entre texto e hipertexto está na tecnologia, no suporte eletrônico. Isto porque, se o texto, conforme venho defendendo, "constitui uma proposta de sentidos múltiplos e não de um sentido único [...], se todo texto é plurilinear em sua construção, então, pelo menos do ponto de vista da recepção, todo texto é um hipertexto" (KOCH, 2002). É este, também, o pensamento de Marcuschi (1999, p.29), quando afirma que "assim como o hipertexto virtualiza o concreto, o texto concretiza a virtualidade".

Mediante o pensamento da autora a hipertextualidade é um conceito amplo que envolve aspectos como não-linearidade e não-sequencialidade (constituição textual plurilinearizada), intertextualidade (texto múltiplo), conectividade (conexão múltipla), interatividade (retroalimentação usuário/Internet), multicentramento (deslocamento não-linear para vários tópicos), virtualidade (matriz de textos potenciais) entre outros.

\subsection{Linguagem}

Os textos-base apresentam a formalidade de textos acadêmicos. Verifica-se a exposição e explicação de conceitos, de teorias e leis de forma que o estudante possa ter o entendimento do conteúdo tratado. Observa-se o pouco uso de analogias, citações de casos e exemplos do cotidiano nessas explicações. Em contrapartida a linguagem é clara apresentando coesão e coerência na exposição das ideias e informações. É de fácil entendimento não deixando margem para dúvidas. No final de cada módulo apresenta as referências utilizadas na construção do textos-base e bibliografia complementar; proporcionando aos estudantes a continuidade de seus estudos.

O término dos textos-base não apresenta resumos cuja finalidade é a revisão dos aspectos centrais trabalhados nos tópicos estudados. Moré et al $(2008$, p. 8) assinalam que o “[...] resumo é a recapitulação das principais questões trabalhadas na unidade, podendo também encaminhar o estudo da próxima unidade”. Esses sequenciamentos favorecem, portanto, a conexão das ideias que foram trabalhadas com aquelas que se seguirão.

Rodrigues (2006) coloca que a linguagem empregada na construção do texto impresso deve ser dialógica, dinâmica, motivadora, multimídia (on line), para que, apesar da distância física, o 
estudante sinta-se estimulado para caminhar no desenvolvimento de sua autonomia; o autor evidencia, também, que estas características não se sustentam se não aparecerem juntas. A linguagem é, portanto, fator preponderante no processo de interação entre o estudante e a fala do professor/tutor materializada no texto impresso.

Nesse sentido o material didático impresso deve ser de fácil compreensão por parte do corpo discente de modo que a interação entre aprendizes e o conteúdo seja a melhor possível; deve manter uma constante contextualização com o conteúdo ministrado; estar disponibilizado em ambiente on-line, de fácil acesso aos interessados propiciando, assim, a difusão do conhecimento e estimular os estudantes para que estes possam construir novos conhecimentos a partir daqueles de que já dispõem e de outros que serão adquiridos.

\section{CONSIDERAÇÕES FINAIS}

Atualmente os meios tecnológicos virtuais multiplicam as oportunidades educacionais em vários níveis, desde a educação básica (regular/Educação de jovens e adultos) até a pós-graduação. No entanto, vale ressaltar que independentemente das inovações didáticas e tecnológicas, o exercício da função docente exige do professor aprendizagem 'contínua e permanente' de sua disciplina, do discurso pedagógico com qual substanciará o conteúdo e dos procedimentos didáticos com os quais estimulará a autonomia dos estudantes visando (re)construir o conhecimento.

As tecnologias didáticas devem ser planejadas com essa finalidade, isto é, a diagramação (arquitetura da comunicação/design instrucional) do material impresso/virtual de ensino/aprendizagem deve materializar a concepção teórico/metodológica no qual os conteúdos serão trabalhados. Observa-se que os textos-base do material didático impresso trabalharam acuradamente os três desafios - exclusão social, valorização da cultura/educação popular e a valorização da condição de adultos - delineados pelos autores em relação a Educação de Jovens e Adultos. Nessa perspectiva os procedimentos de ensino-aprendizagem tiveram por meta principal impregnar os estudantes da concepção didático/pedagógica subjetivada no processo.

Nesse sentido a linguagem textual apresentou-se com coesão e coerência tanto em relação a construção dos textos quanto em relação ao aspecto teórico/metodológico. A diagramação do material impresso buscou dar forma adequada à apresentação do texto viabilizando uma linguagem clara, concisa e hipertextual tanto em relação a estruturação tipográfica quanto em função do uso de caixas periféricas. A organização tipográfica resultou em textos-base delimitados e sequenciados sob o aspecto gráfico. 
Considerando as caixas periféricas como parte integrante ao corpo do texto, elas foram bastante exploradas e, portanto, deram o tom de hipertextualidade ao conjunto de textos-base. Foram utilizadas inclusive para autoavaliações, avaliações e interações via fórum.

Por fim, deve-se considerar a importância da avaliação dos materiais didáticos para EaD pelo público-alvo. Esse procedimento pode resultar em sugestões valiosas no sentido da organização textual/hipertextual e na estruturação gráfico/editorial.

\section{REFERÊNCIAS}

AVERBUG, Regina. Material didático impresso para a educação à distância: tecendo um novo olhar. Colabor@: Revista Digital da Comunidade Virtual de Aprendizagem Rede de Instituições Católicas de Ensino Superior, Santos, vol. 2, n. 5, p. 16-31, ago./set., 2003.

BARRETO, Cristiane Costa. Desenho instrucional em materiais didáticos impressos - uma boa ideia! In: BARRETO, Cristiane Costa (org.). Planejamento e Elaboração de Material Didático Impresso para Educação a Distância. Rio de Janeiro, Fundação CECIERJ, 2007, 291 p.

BRAGLIA, Israel \& GONÇALVES, Berenice. Abordagem sistemática do design instrucional na implementação de hipermídias para aprendizagem. In: Anais do $4^{\circ}$ Congresso Nacional de Ambientes Hipermídia para Aprendizagem. Florianópolis, 5 a 7 de novembro. 2009. Disponível em http://wright.ava.ufsc.br/ alice/conahpa/anais/2009/cd conahpa2009/papers/ final134.pdf. Acesso em 02 de outubro de 2014.

CARVALHO, Ana Maria Ferreira et al. Gerenciamento do processo de elaboração de materiais didáticos para o curso de bacharelado em Biblioteconomia na modalidade a distância no Brasil. In: Anais del Primer Congreso Virtual De Innovación Didáctica Al Servicio Del Docente Y Profesional En Ciencias Documentales. Madri: Congressos Web, 2013. Disponível em http://www.congresosweb.info/index.php/areas-tematicas-2013/Congreso $\% 202013 /$ educacion-y-formacion profesional/gerenciamento-do-processo-de-elaboracao-de-materiaisdidaticos-para-o-curso-de-bacharelado-em-biblioteconomia-na-modalidade-a-distancia-no-brasil Acesso em 27 de jul. 2014.

FILATRO, Andrea. Design Instrucional Contextualizado. São Paulo: Senac, 2004.

KOCH, Ingedore. G. Villaça. Hipertexto e Construção do Sentido. Alfa: Revista de Linguística. Vol. 51, no 1, p. 23-38, 2007. Disponível em: http://seer.fclar.unesp.br/alfa/article/viewFile/ 1425/1126. Acesso em set. 2014.

KULPA, Cínthia Costa; PINHEIRO, Eluza Toledo; SILVA, Régio Pierre. A Influência das Cores na Usabilidade de Interfaces Através do Design Centrado no Comportamento Cultural do Usuário. Perspectivas em Gestão \& Conhecimento, João Pessoa, vol. 1, Número Especial, 2011, p. 119136. Disponível em: http://periodicos.ufpb.br/ojs2/index.php/pgc. Acesso em set 2014.

LEITÃO, Cleide. Elaboração de material didático impresso para programas de formação à distância: orientações para autores. Porto Alegre: Edições UFRGS, 2005. Disponível em http://www.ufrgs.br/nucleoead/documentos/ENSPMaterial.pdf. Acesso em 09 de julho de 2014. 
LIMA, Vera Lopes de Abreu. Legibilidade e leiturabilidade das bulas de medicamentos presentes no tratamento de pacientes cardíacos. Rio de Janeiro, 169 f. Dissertação de Mestrado (Artes e Design), Pontifícia Universidade Católica do Rio de Janeiro, 2007.

MORÉ, Rafael Pereira Ocampo. Processo de elaboração do material didático do curso de graduação em administração, modalidade a distância. In: Anais do XIV Congresso Internacional ABED De Educação A Distância. Santos: ABED, 2008. Disponível em: http://www.abed.org.br/congresso2008/tc/5112008102953am.pdf. Acesso em out. 2014.

OTA, Marcos et al. Atualização e Ressignificação de Materiais Didáticos em Educação à Distância: desafios instrucionais na produção de novas mídias. Revista Trilha Digital. vol. 1, no 1. São Paulo, 2013. Disponível em http://editorarevistas.mackenzie.br/index.php/TDig/article/view/5900. Acesso em 27 de jul. de 2014.

PEREIRA, Márcio Mota. Avaliação Quali-Quantitativa do Material Didático Utilizado em um Curso de Aperfeiçoamento na Modalidade a Distância. Monografia (Curso de Pósgraduação Lato sensu em Planejamento, Implementação e Gestão de Educação a Distância), Universidade Federal Fluminense, 2014.

PRETI, Orestes. (Org). Produção de Material Didático Impresso: Orientações Técnicas e Pedagógicas. Cuiabá: UAB/UFMT, Cuiabá, 2010, 209 p. Disponível emhttp://www.uab.ufmt.br/ uab/images/livros download/producao material didatico impresso oreste preti.pdf. Acesso em 09 de setembro de 2014.

RAMOS, Roberto Paes de Carvalho; ABREU-FIALHO, Ana Paula e RABELO, Carlos Otoni. Arquitetura da informação. In BARRETO, Cristine Costa (org.). Planejamento e elaboração de material didático impresso para Educação a Distância. Rio de Janeiro: Fundação CECIERJ, 2007, 291 p.

REIS, Guilhermo Almeida dos. Centrando a Arquitetura de Informação no Usuário. Dissertação de Mestrado em Ciência da Informação. Escola de Comunicação e Artes, Universidade de São Paulo, São Paulo, 2007, 250 p.

RODRIGUES, Adriane Pires et all. Producão do material didático para o módulo "ferramentas de autoria para a produção de hipertexto na educação" do programa mídias na educação. In: Anais do $3^{\circ}$ Congresso Brasileiro de Extensão Universitária, Florianópolis. $3^{\circ}$ Congresso Brasileiro de Extensão Universitária, 2006.

SALES, Mary Valda Souza. Uma Reflexão Sobre a Produção do Material didático para EaD. In: Anais do XII Congresso Internacional ABED de Educação a Distância. Florianópolis: ABED, 2005. Disponível em: http://www.abed.org.br/congresso2005/ por/pdf/044tcf5.pdf. Acesso set. 2014.

SAMPAIO, Grace Maria Cavalcante. Compreensibilidade de textos contínuos em interfaces gráficas. Campina Grande, 2002, 143 f. Dissertação de Mestrado - Centro de Ciências e Tecnologia, Universidade Federal da Paraíba.

SAVIANI, Demerval. A Pedagogia no Brasil: história e teoria. Campinas: Autores Associados, 2008. 
SILVA, Luciene Santos Pereira da. A produção textual de material didático para educação a distancia. Dissertação (Mestrado em Ciência da Linguagem), Universidade Católica de Pernambuco, 2010, 124 f. Disponível em http://www.unicap.br/tede// tde busca/ arquivo.php?codArquivo=542. Acesso em 07 de julho de 2014.

SOUZA, Antônio Artur de (Org.). Educação de Jovens e Adultos na Diversidade. Belo Horizonte: CAED-UFMG, 2013, 223 p.

SOUZA, Caroline Nagel Moura de. A importância da mediação pedagógica transdisciplinar em EAD que se utiliza de imagens para a busca do conhecimento e da efetivação do aprendizado. Visão Global, vol. 12, nº. 2, 2009. Disponível em: http://editora.unoesc.edu.br/index.php/ visaoglobal/article/view/624/285. Acesso em jul. 2015. 